\title{
LA JURISPRUDENCIA \\ DEL TRIBUNAL CONSTITUCIONAL, CONMEMORACIÓN DE LA CONSTITUCIÓN
}

\author{
INTERVENCIÓN CON MOTIVO \\ DEL CUARENTA ANIVERSARIO \\ DE LA CONSTITUCIÓN
}

PEDRO J. TENORIO SÁNCHEZ 


\section{SUMARIO}

I. CONMEMORAR NO ES RECORDAR. II. ELOGIO DE SU TRAYECTORIA GLOBAL. III. ELOGIO DE LOS ÚLTIMOS AÑOS. IV. DEFENSA DE LA CONSTITUCIÓN FRENTE A LAS TENDENCIAS CENTRÍFUGAS 


\title{
LA JURISPRUDENCIA DEL TRIBUNAL CONSTITUCIONAL, CONMEMORACIÓN DE LA CONSTITUCIÓN
}

\section{Intervención con motivo del cuarenta aniversario de la Constitución ${ }^{1}$}

\author{
PEDRO J. TENORIO SÁNCHEZ. \\ Catedrático de Derecho Constitucional. \\ UNED. Madrid
}

\section{CONMEMORAR NO ES RECORDAR}

Es un placer y un honor dirigir a los compañeros presentes y a los alumnos de la UNED, a los que se transmite este acto por internet, unas palabras en esta mesa redonda organizada por la UNED para conmemorar el cuarenta aniversario de la aprobación de nuestra Constitución.

La palabra conmemoración tiene un significado distinto del recuerdo subjetivo de un hecho o de un acontecimiento que convertimos en presente trayéndolo de nue-

1 El 26 de junio de 2018, la UNED, a iniciativa de la Profesora Doña Yolanda Gómez Sánchez, Directora de la Escuela Internacional de Doctorado, se organizó un acto conmemorativo del XL Aniversario de la aprobación de la Constitución en el que intervinieron el propio Rector de la UNED, el Presidente del Tribunal constitucional, el Decano de la Facultad de Derecho, el Director del Centro de Estudios Políticos y Constitucionales y la propia Directora de la escuela Internacional de Doctorado. Los Profesores Don Antonio Torres del Moral y Don Carlos Vidal Prado presentaron los dos volúmenes del número monográfico de la Revista de derecho Político de la UNED con motivo del XL aniversario de la Constitución Española de 1978. Y tuvo lugar una Mesa redonda moderada por Don Antonio Torres en la que intervinieron los Profesores Don Francisco Balaguer Callejón, Doña Paloma Biglino, Doña Teresa Freixes, Don Raúl Canosa y Don Pedro Tenorio. Publicamos a continuación, con ligeras variaciones, el texto de la intervención del Profesor Tenorio. 
vo a nuestra memoria. Significa actualizar, vivir de nuevo, revivir el hecho que se conmemora, renovarlo.

Pues bien, se recordará que C.E. Hughes, Presidente del Tribunal Supremo de Estados Unidos, ${ }^{2}$ vino a decir que la Constitución es la ley suprema del país, pero que en definitiva acaba siendo lo que el Tribunal Supremo dice que es. Si en EEUU, donde corresponde al Tribunal Supremo el control de constitucionalidad, la Constitución es lo que el Tribunal Supremo dice que es, entre nosotros, podemos decir que la Constitución es lo que el Tribunal Constitucional dice que es.

Así pues, la labor del Tribunal Constitucional, la aplicación del texto y de los valores constitucionales, es, de alguna manera, una conmemoración permanente de nuestra Constitución.

De ahí que sea muy oportuno, en un acto de conmemoración de la aprobación de nuestra Constitución, referirnos al trabajo desempeñado por el Tribunal Constitucional durante todos estos años, concretamente desde el 11 de agosto de 1980, fecha en que dictó su primera resolución (ATC 1/1980, de 11 de agosto).

\section{ELOGIO DE SU TRAYECTORIA GLOBAL}

Muchos son los elogios que se han dirigido, con justicia, a la labor de nuestro Tribunal Constitucional, tanto referidos al conjunto de su trayectoria, como más concretamente a la de los últimos años.

Comenzando por los méritos que ha contraído a lo largo de toda su trayectoria, hemos de señalar que ha dictado una jurisprudencia muy valiosa, tanto en el ámbito de los derechos fundamentales como en el de la construcción del Estado autonómico.

Sus resoluciones, inspiradas en un antiformalismo compatible con el rigor técnico y conceptual, son fruto de la fecunda colaboración entre jueces, profesores y otros profesionales del Derecho. Sus sentencias y autos han tenido desde siempre un planteamiento didáctico, han pretendido ser entendidas, persuadir, no zanjar los conflictos basándose solo en su fuerza o en su autoridad.

En el ámbito de los derechos fundamentales, su jurisprudencia ha informado e informa la aplicación de la Constitución por todos nuestros tribunales, irradiando los valores constitucionales, que no son sino los de las democracias occidentales, a todo el Poder judicial y a todos los operadores jurídicos.

Se critica a veces que el Tribunal Constitucional solo admite un escaso porcentaje de los recursos de amparo que ante él se interponen. Pero cuando se subraya esto, se olvida el escasísimo número de condenas que recibe España del Tribunal Europeo de Derechos Humanos, muy por debajo del que reciben otras democracias más anti-

${ }^{2}$ Lo que dijo exactamente fue que «el Tribunal es el intérprete final de las leyes del Congreso. Las leyes vienen a la prueba judicial y una ley federal significa, finalmente, lo que el Tribunal dice que significa», citado por García Pelayo, Manuel, Derecho Constitucional Comparado, en Obras completas, vol. I, Centro de Estudios Constitucionales, Madrid, 1991, p. 579. 
guas como son las de los países fundadores de la Unión Europea. Hay que reconocer que si España merece pocas condenas del Tribunal Europeo de Derechos Humanos y a su vez el Tribunal Constitucional admite pocos recursos de amparo, entonces es que los derechos fundamentales, no ya tal y como los concibe nuestro Tribunal Constitucional, sino como lo hace el propio Tribunal Europeo de Derechos Humanos, son aplicados entre nosotros de manera generalizada por los órganos jurisdiccionales.

Por otra parte, la jurisprudencia constitucional en el ámbito de los derechos fundamentales ha supuesto una gran renovación, a pesar de la supervivencia durante muchos años de leyes preconstitucionales en amplios sectores del ordenamiento jurídico. La innovación ha sido amplia y profunda en el Derecho penal, que viene a ser el envés del Derecho Constitucional, o en el Derecho procesal, superando su tendencia al casuismo, la rigidez y el formalismo, y construyendo en su lugar una serie de principios básicos que lo sintetizan.

Todavía en el ámbito de los derechos fundamentales, nuestro Tribunal se ha colocado entre los tribunales europeos que protagonizan el diálogo con el Tribunal de Justicia de la Unión Europea, ese nuevo actor que se esfuerza en encontrar su sitio en el sistema europeo de protección de los derechos.

En el ámbito de la resolución de conflictos entre Estado y Comunidades Autónomas, la importancia de la jurisprudencia de nuestro Tribunal Constitucional, es tal que se ha calificado a nuestro Estado como Estado jurisdiccional autonómico. Nuestro Tribunal ha alumbrado una técnica de resolución de conflictos original y lograda, afrontando ante todo en sus sentencias la calificación de lo controvertido para a continuación aplicar al conflicto planteado el régimen constitucional correspondiente, que ha procurado construir de manera coherente, ateniéndose a sus propios precedentes.

\section{ELOGIO DE LOS ÚLTIMOS AÑOS}

Si pasamos a referirnos a los últimos años, concretamente a los transcurridos desde 2007, cuando se hizo una importante reforma de la Ley Orgánica del Tribunal Constitucional, el balance también resulta decididamente satisfactorio. Baste decir que el temor por el colapso del Tribunal que existía a la altura de 2004, reconocido por los propios Presidentes del Tribunal, en la actualidad ha desaparecido, toda vez que nuestro Tribunal lleva su trabajo prácticamente al día.

\section{DEFENSA DE LA CONSTITUCIÓN FRENTE A LAS TENDENCIAS CENTRÍFUGAS}

Gran mérito de nuestro Tribunal Constitucional, que supone una aportación destacable a la historia de la justicia constitucional es la forma en que ha afrontado los diferentes asuntos en que estaban implicadas las tendencias centrífugas que nos afectan. 
En este ámbito, se han criticado tanto algunas decisiones de alcance muy general como otras puntuales.

Entre las primeras, se ha lamentado la excesiva contundencia de la STC 76/1983, de 5 de agosto, sobre la LOAPA, que en la práctica ha inducido al Estado a abandonar cualquier intento de ley de principios armonizadores, a pesar de la previsión clara de art 150 de nuestra Constitución ${ }^{3}$.

También se le ha reprochado falta de rigor al conocer de las contradicciones entre la atribución de competencias que hace la Constitución y la que realizan los Estatutos de autonomía. En efecto, es sabido que algunos Estatutos de autonomía atribuyen a algunas Comunidades Autónomas como exclusivas determinadas competencias en abierta contradicción con la calificación que hace la Constitución de diversas competencias igualmente como exclusivas. Y el Tribunal, en lugar de reconocer que la atribución estatutaria es inconstitucional, o de hacer una «interpretación conforme» de los Estatutos, optó por considerar que en realidad prácticamente la generalidad de las competencias son compartidas, lo que resta o priva de eficacia al tenor literal de la Constitución y traslada al Tribunal la resolución de un excesivo número de conflictos sin poder contar para la resolución de los mismos con un punto de referencia firme y sólido ${ }^{4}$.

Y esto, a su vez, habría tenido como consecuencia el relativo vaciamiento de preceptos claros de nuestra Constitución y ha difundido la convicción de que se puede forzar la Constitución ilimitadamente siempre que haya una voluntad política suficientemente firme para hacerlo. En este sentido, se han criticado las sentencias que han dado pie a la creación de las embajadas catalanas (STC 165/1994, de 26 de mayo, FJ 5) o las que han permitido una virtual expulsión del español como lengua

${ }^{3}$ O, quizás, lo que ha habido es una interpretación equivocada por parte del Estado. Aquella Sentencia, es verdad que por una parte, inducía a pensar en el carácter excepcional de este tipo de normas, diciendo que «el art. 150.3 constituye una norma de cierre del sistema, aplicable sólo a aquellos supuestos en que el legislador estatal no disponga de otros cauces constitucionales para el ejercicio de su potestad legislativa o éstos no sean suficientes para garantizar la armonía exigida por el interés general» (FJ 3). Pero también hay que reconocer que aquella Sentencia dijo que se podía utilizar tal institución «cuando, en el caso de competencias compartidas, se aprecie que el sistema de distribución de competencias es insuficiente para evitar que la diversidad de disposiciones normativas de las Comunidades Autónomas produzca una desarmonía contraria al interés general de la nación» (FJ 3).

4 En efecto, ya desde sus primeras Sentencias, el Tribunal señaló «el sentido marcadamente equívoco con el que el adjetivo "exclusivo» se utiliza tanto en el texto de la Constitución como en el de los Estatutos de Autonomía hasta ahora promulgados» (STC 37/1981, de 16 de noviembre, FJ 1.3). Pero es que en la STC 135/1995, de 5 de octubre, FJ 4.3, dijo que «es evidente que la operación jurídica de sumar competencias exclusivas da por resultado su transformación en compartidas». Acerca del orden constitucional de competencias y ordenamientos, v. el comentario al art. 149.3 CE de Borrajo Iniesta, Ignacio, en Casas Baamonde, María Emilia, y Rodríguez-Piñero, Miguel (directores), Comentarios a la Constitución Española. XXX Aniversario, Fundación Wolters Kluwer España, pp. 2479 y ss. 
vehicular de la enseñanza en Cataluña ${ }^{5}$. En cuanto a la virtual expulsión del español como lengua vehicular de la enseñanza en Cataluña, no resulta fácil señalar las Sentencias de nuestro Tribunal decisivas, ya que son muchas las que han tratado la cuestión de la lengua para acabar sorteando el muy claro artículo 3 de nuestra Constitución, que proclama no solo que el castellano es la lengua española oficial del Estado, sino que todos los españoles tienen el deber de conocerla y el derecho a usarla. Si en unas primeras Sentencias se decía que «es evidente que ninguna Comunidad Autónoma puede encontrar en la regulación de la materia lingüística una competencia ${ }^{6}$, a partir de la STC 74/1989, de 21 de abril, parece admitirse la existencia de alguna competencia autonómica con contenido concreto, para pasar posteriormente, concretamente en la STC 87/1997, de 24 de abril, a la aceptación de lo que algunos autores $^{7}$ consideran concurrencia competencial en materia lingüística.

Pero seguramente algunos de los que me escuchan alegarían en sentido contrario que nuestro Tribunal Constitucional ha compensado estas opciones descentralizado-

5 En efecto, la STC 165/1994, de 26 de mayo, FJ 5, aunque concretó como contenido del título competencial «relaciones internacionales en la celebración de los tratados, representación exterior de los tratados y creación de obligaciones internacionales y responsabilidad internacional del Estado» ha permitido crear el concepto de «acción exterior de las Comunidades autónomas» que, sin fundamento en la Constitución, ha acabado configurando la materia relaciones internacionales, que sí está prevista en la Constitución, tan solo como un límite a la acción exterior de las Comunidades Autónomas. De esta manera, una competencia configurada con claridad como exclusiva en la Constitución se ha convertido en un mero límite externo de una supuesta competencia genérica de las Comunidades Autónomas que no es propia de una entidad territorial no soberana. V. Ripol Carulla, Santiago, Comentario al artículo 149.1.3. ${ }^{a}$ CE, en Casas Baamonde, María Emilia, y Rodríguez-Piñero, Miguel (directores), Comentarios a la Constitución Española. XXX Aniversario, Fundación Wolters Kluwer España, pp. 2281 y ss., especialmente pp. 2282 y 2283.

6 STC 82/1986, de 26 de junio, FJ 5, según la cual «es evidente que ninguna Comunidad Autónoma puede encontrar en la regulación de la materia lingüística una competencia que la habilite para dictar normas relativas a la organización y funcionamiento de la Administración estatal, como puede hacerlo con respecto a la propia Administración autonómica, e incluso a la local en virtud de lo que establezcan los respectivos estatutos»; STC 123/1988, de 23 de junio, FJ 5, según la cual «la atribución de la regulación de la cooficialidad y sus efectos no puede suponer una atribución de competencias específicas más allá del marco establecido en el reparto que llevan a cabo la Constitución y los Estatutos de Autonomía»; STC 69/1988, de 19 de abril, que dice que el art. 3.3 del Estatuto de Autonomía de Cataluña «más que enunciado de una norma competencial, expresa un mandato —STC 82/1986, de 26 de junio- o un deber —STC 6/1982, de 22 de febrero- que impone a las instituciones y órganos autonómicos para que, con ocasión de sus competencias propias, procuren alcanzar los objetivos marcados en aquel precepto estatutario, estando, por tanto, en presencia, no de una competencia en sentido propio, sino de un compromiso de promoción de la normalización lingüística, cuyo fundamento primero se encuentra en el art. 3.3 de la Constitución y que, con cobertura en la citada regla del Estatuto, se desarrolla en la Ley 7/1983, de 18 de abril, del Parlamento de Cataluña. Este mandato de normalización del uso de las lenguas oficiales en el territorio catalán no confiere, pues, competencia específica alguna a la Comunidad Autónoma frente al Estado».

${ }^{7}$ Fosas Espadaler, Enrique, Comentario al art. 3 CE, en María Emilia, y Rodríguez-Piñero, Miguel (directores, Comentarios a la Constitución Española. XXX Aniversario, Fundación Wolters Kluwer España), pp. 64 y ss., especialmente p. 72.

N. ${ }^{\circ} 103$, septiembre-diciembre 2018, págs 441-450 
ras con una interpretación amplia de lo que la Constitución califica como bases o como básico y que está en manos del Estado.

En todo caso, y aunque no lo haya hecho siempre a gusto de todos, resulta justo reconocer que hasta la fecha, y tal vez especialmente en los últimos años, nuestro Tribunal Constitucional ha tenido que afrontar un problema que no encuentra parangón en ningún otro país del mundo, y que lo ha hecho con éxito y haciendo alguna interesante aportación a la historia de la justicia constitucional.

Es verdad que existen antecedentes en el Derecho comparado de casos en que tribunales supremos o constitucionales han tenido que intervenir en intentos de secesión o de falta de acatamiento a sus resoluciones por los propios poderes públicos. En este sentido, se podrían traer a colación algunas resoluciones muy poco conocidas del Tribunal Supremo de EEUU que quedaron en el olvido con motivo de la Guerra de Secesión, una sentencia del Tribunal Constitucional federal austriaco que fue incumplida por un Estado federado y el influyente Dictamen del Tribunal Supremo de Canadá sobre la secesión de Quebec de 20 de agosto de $1998^{8}$.

El Tribunal Supremo de Estados Unidos demostró una actitud deferente respecto de los poderes federales en los Prize Cases (1863) ${ }^{9}$, admitiendo implícitamente que el Presidente podía reaccionar con actos típicos de un estado de guerra en el caso de la «rebelión» de los estados del sur, sin tener que esperar una expresa deliberación del Congreso.

Solo en un caso el Tribunal Constitucional austriaco ${ }^{10}$ ha estimado una acusación contra un presidente de un Land, limitándose a declarar la ilegalidad de su actuación sin imponerle consecuencias jurídicas adicionales ${ }^{11}$ en el que tal vez haya sido el caso más grave de crisis político-constitucional originada en el incumplimiento de una sentencia constitucional fuera de nuestras fronteras.

El Dictamen del Tribunal Supremo de Canadá sobre la secesión de Quebec, ciertamente ha sido respetado, pero porque opta por lo que suele llamarse impropiamente una solución salomónica que en definitiva traslada el problema a los actores políticos. Situándose en la tradición jurídica de los países de la Commonwealth, desborda el texto escrito de la Constitución, que queda relativizada por lo que los magistrados llaman «la arquitectura interna de la Constitución», constituida por los que denomina «cuatro principios fundamentales e informa-

${ }^{8}$ V. el excelente trabajo de Chacón Piqueras, Carmen y Ruiz Robledo, Agustín, «El Dictamen sobre la secesión de Quebec: un comentario», en Revista Teoría y Realidad Constitucional, número 3, de 1999.

9 Vease Gross O., "Chaos and Rules: Should Responses to Violent Crisis Always Be Constitucional?», en 112 Yale Law Journal, 2003, pág. 1011 y sigs. Citado por Benazzo, Antonela: L'emergenza nel conflitto fra libertá e sicurezza, G. Giappichelli editore, Torino, 2004 ; pp. 80 y ss.

10 Acerca de las incidencias de ejecución de Sentencias del Tribunal Constitucional, v. el excelente trabajo de Arzoz SANTISTEBAN, Xabier, «Los poderes de ejecución de los Tribunales Constitucionales alemán y austriaco», en Revista Española de Derecho Constitucional, 108, pp. 13 a 49. Tomamos de las páginas 45 y 46 las incidencias relativas a la Sentencia de 13 de diciembre de 2001.

11 VfSlg 10.510, de 28 de junio de 1985. 
dores de la constitución», aunque acaba enumerando cinco: «el federalismo, la democracia, el constitucionalismo y la primacía del derecho, así comoel respeto de las minorías».

Pero ningún Tribunal Constitucional ha tenido que pronunciarse sobre un Estatuto tan gravemente inconstitucional como el catalán de $2006^{12}$, ni sobre una inacabable serie de leyes autonómicas no ya abiertamente inconstitucionales, sino aprobadas por las propias autoridades de una Comunidad Autónoma con el propósito reconocido de construir un Estado distinto del constitucional, que disuelva la unidad del propio Estado constitucional. Como tampoco ha tenido que afrontar ningún Tribunal Constitucional la abierta desobediencia por las autoridades de un Estado federado o de una Comunidad Autónoma de una serie ilimitada de resoluciones del Tribunal Constitucional.

Destacaré en este ámbito para concluir una decisión sumamente creativa y efectiva de nuestro Tribunal que puede considerarse una aportación a la historia de la justicia constitucional, aunque a primera vista pueda parecer un detalle muy técnico. Me refiero al ATC 126/2017, de 20 de septiembre, que acordó la imposición de multas coercitivas para garantizar la ejecución de las resoluciones del Tribunal. El Gobierno había promovido incidente de ejecución en relación con cinco providencias del Pleno del Tribunal por las que se había acordado la suspensión de varias resoluciones de las autoridades de la Comunidad Autónoma de Cataluña ${ }^{13}$; en particular, se entendía producido el incumplimiento de estas providencias por los miembros de la sindicatura electoral de Cataluña, al haber procedido estos a llevar a cabo una serie de

12 A la STC 31/2010, de 28 de junio, que declaró inconstitucional parte del Estatuto catalán de 2006 se le ha imputado incomprensión de los legítimos anhelos autonomistas catalanes. Sin embargo, si partimos de una comparación aséptica de la Constitución con el texto del Estatuto, si algo se puede reprochar a esa sentencia, es más bien, haber transigido con varias inconstitucionalidades claras y haber intentado evitar declarar otras haciendo pseudo interpretaciones conformes. Pero por lo demás el mero hecho de haber llegado a confeccionar una sentencia que diera respuesta a aquel recurso de inconstitucionalidad es una gesta que no encuentra parangónen el Derecho comparado.

Por cierto, que en aquella sentencia hubo votos particulares, y tal vez asumiendo parte de las críticas que a la misma se han dirigido, nuestro Tribunal Constitucional, en lo sucesivo, parece haberse esforzado en aprobar las resoluciones relacionadas con la cuestión separatista por unanimidad, lo que se puede constatar repasando las mismas, ya que son muy excepcionales los votos particulares. De esta manera nuestro Tribunal ha declarado inconstitucionales unas leyes de la Comunidad Autónoma catalana que abiertamente pretendían construir un Estado independiente en indiscutible contradicción con nuestra CE. El esfuerzo de nuestro Tribunal Constitucional para dotar de esta manera de más autoridad a sus sentencias se ha revelado políticamente estéril.

13 Respectivamente: a) de la resolución 807/XI, del Parlamento de Cataluña, por la que se designan miembros de la sindicatura electoral; b) del Decreto 140/2017, de 7 de septiembre, de normas complementarias para la celebración del referéndum de autodeterminación de Cataluña; c) de la Ley 19/2017, de 6 de septiembre, del referéndum de autodeterminación, del Parlamento de Cataluña; d) del Decreto 139/2017, de 6 de septiembre, por el que se convoca el referéndum de autodeterminación de Cataluña y e) de la Ley 20/2017, de transitoriedad jurídica y fundacional de la República, del Parlamento de Cataluña. 
actuaciones para la celebración del referéndum ${ }^{14}$. Pues bien, la dimisión inmediata de los afectados, a raíz de la imposición de las multas coercitivas, privó de toda apariencia de seriedad al proceso referendario de manera notoria.

Ciertamente son todavía muchos los retos que tiene pendientes nuestro Tribunal Constitucional.

Pero difícilmente se podría sostener que, una institución tan joven en la organización del Estado, y no digamos ya en la organización de la comunidad política, no se ha ganado un lugar relevante en el constitucionalismo en general y en el nuestro en particular, siempre desarrollando su labor de conmemoración de la Constitución.

${ }^{14}$ Las siguientes actuaciones: a) constituirse como sindicatura electoral de Cataluña; b) designar a los miembros de las sindicaturas de demarcación; c) ampliar el plazo para la presentación de organizaciones interesadas en el referéndum y validar el denominado «Manual de Instrucciones para los representantes de la Administración y para los miembros de las Mesas Electorales» y d) publicitar las organizaciones electorales que han sido admitidas para participar en el referéndum. El Auto impuso sendas multas coercitivas diarias de 12.000 euros a los siete miembros de la Sindicatura electoral de Cataluña, y de 6.000 euros a los quince miembros de las sindicaturas electorales de demarcación. Se declara que la multa coercitiva resulta adecuada para restablecer el orden constitucional perturbado, además se afirma que ésta resulta necesaria, en el sentido de que no existe la posibilidad de imposición de una medida menos gravosa. En cuanto a la ponderación de la cuantía de la multa el Auto distingue entre el grado de responsabilidad atribuido a los miembros de la Sindicatura electoral de Cataluña y a los miembros de las sindicaturas electorales de demarcación, y considera las cantidades proporcionadas atendiendo a las circunstancias que concurren en ellos. 